\title{
Delayed Puberty, CTCAE
}

National Cancer Institute

\section{Source}

National Cancer Institute. Delayed Puberty, CT CAE. NCI Thesaurus. Code C55742.

A disorder characterized by unusually late sexual maturity. 